\title{
Semantic facilitation and lexical access during sentence processing
}

\author{
MICHELLE A. BLANK and DONALD J. FOSS \\ University of Texas at Austin, Austin, Texas 78712
}

\begin{abstract}
An experiment was conducted testing predictions derived from context-dependent and context-independent models of lexical access. Four types of unambiguous test sentences were constructed. The direct object of each test sentence was preceded by a verb that was either semantically related or unrelated to it, and by an adjective that was semantically related or unrelated. Context-dependent models predict that the speed with which the object noun is retrieved from the mental lexicon will be faster when the verb and/or the adjective is semantically related; context-independent models predict no such facilitation. Forty-four subjects each heard 32 test sentences and were asked to monitor within the sentence for a word-initial target phoneme. The target phoneme occurred on the word following the object noun. Reaction times to detect the targets were obtained. According to context-dependent models, these times should be shorter when related words precede the object noun, and that is what was found. It was also observed that the facilitation effects due to the related verbs and adjectives were additive. Implications of these results were discussed.
\end{abstract}

We typically understand sentences without apparent effort. This is in spite of the amazingly complex psychological processes required to transform an acoustic signal into a meaningful representation. One general concem of psycholinguistic research is to characterize those processes underlying our facile ability to comprehend sentences.

Upon hearing a sentence, a listener derives phonetic, phonological, lexical, syntactic, and semantic information from its acoustic representation. Previous studies have shown that the processes that abstract these types of information interact with each other (Marslen-Wilson, 1976). Thus, phoneme identification can be affected by higher order organization at the syllabic, word, or sentential level (Cole, 1973; Shankweiler, Strange, \& Verbrugge, 1977; Warren \& Sherman, 1974); redundancy provided by syntactic and semantic context influences word identification (Meyer \& Schvaneveldt, 1971; Morton, 1969; Tulving \& Gold, 1963); the context of an embedding paragraph affects the comprehension of a single sentence (Bransford \& McCarrell, 1974); and, finally, prose-passage comprehension can be facilitated by the presence of thematic information (Bransford \& Johnson, 1972; Dooling \& Lachman, 1971).

This research was funded in part by NICHHD Grant HD00439 and by NIMH Grant MH29891. Requests for reprints should be sent to Donald J. Foss, Psychology Department, University of Texas at Austin, Austin, Texas 78712. This article is based on a paper presented at the Midwestern Psychological Association, Chicago, 1977. We thank our friend and colleague Randy Diehl for his time in reading this manuscript and his many helpful suggestions. We also thank Ken Forster and another anonymous reviewer for their many suggestions which helped improve this paper. In addition, the senior author thanks her office mate Pamela Holley-Wilcox for her time and patience while this manuscript was being written.
This paper is concerned with the effects of prior semantic context on word identification. ${ }^{1}$ Numerous studies have found that the identification of a word in a list is facilitated by the prior occurrence in the list of semantically related words (e.g., Fischler, 1977; Meyer \& Schvaneveldt, 1971). At least two classes of models have been proposed to explain such observations. Forster (1976) explains the facilitative effect by proposing a search model of lexical access in which related words are interconnected or cross-referenced within the mental lexicon. When one entry has been retrieved, other related lexical items can be accessed via the system of interconnections. According to Forster, this cross-referencing, which is determined by semantic factors, provides an access route that is independent of the access route based on sensory information. Presumably, the semantic search and sensory search proceed simultaneously. Semantic facilitation occurs when the semantic search is faster than the sensory search. The facilitative effect can also be explained within the framework of Morton's (1969) logogen model. This model assumes that a lexical entry (the logogen) has a threshold value associated with it that defines the amount of information that must be received in order for it (i.e., the logogen) to be activated or accessed. Both sensory and semantic information are accepted as input to the logogen system. These two types of information combine to activate logogens in such a way that there is a tradeoff relationship between them. More specifically, when a logogen receives semantic input from a previously accessed related word, there is a decrease in the amount of sensory information that is needed to bring it above its threshold level. Consequently, the time to access the logogen from the onset of the relevant sensory informa- 
tion will be less than when no semantically related word preceded it because less sensury processing will be necessary.

To date, however, it is unclear whether word identification in sentences is facilitated by the prior occurrence of semantically related words. The problem is interesting for two reasons. First, it bears directly on our choice between the two general classes of lexical access models. Second, it is relevant to discussions of the effects of lexical ambiguity on sentence processing.

Consider first the problem as it bears on models of lexical access. According to Forster's (1976) search model, a correct lexical entry is retrieved via the continuous reduction of the size of the search set. In terms of this model, the occurrence of a semantically related word in a list facilitates lexical access by reducing the size of the search set so that the semantically governed search locates the appropriate entry faster than the independent, but simultaneous, acoustic/ phonetic (i.e., sensory) based search. In discussing lexical access in sentences, Forster distinguishes between context effects that depend on the prior occurrence of semantically related words (like those observed in list studies) and context effects that depend on the meaning of preceding sentence fragments. He proposes that only in the former case can listeners effectively use the semantic network of cross-references to increase the speed of the semantic search relative to the sensorybased search. According to Forster (1976), "the semantic context provided by a sentence fragment does not provide anything like the same facilitation as a semantically related word" (p. 280). In support of this claim, Forster cites evidence from his laboratory. For example, in one line of research, he has shown that words that were predictable from a sentence context were not named faster than those that were less predictable (cf. Schuberth \& Eimas, 1977, for discussion of contrary findings). Thus, Forster concludes that lexical access in sentences will not be facilitated by semantic context provided by a sentence fragment. In addition, Forster considers it "most implausible" to assume that there will normally be a particular word in a sentence that will establish a specific link to another word in the sentence. More precisely, Forster (Note 1) argues that although one can certainly find examples of sentences that contain related or associated pairs of words, "their frequency scarcely justifies an elaborate scanning of the associates of every word in a sentence in the hope that a pair of associatively related words will be present"' (p. 88).

Hence, Forster dismisses any consideration of the role of cross-referencing in lexical access during sentence processing. As Forster (1976) points out, "it seems quite clear that in the case of sentences, the appropriate cross-reference would have to come from an internal representation of a situation, not a word or any other kind of linguistic entity" (p. 280). In essence, Forster argues that his system of cross-references between lexical entries does not predict semantic facilitation in sentences because (1) it is highly unlikely that individual words in sentences will be semantically related to each other, and (2) the way in which a sentence fragment can constrain the possible words that are likely to occur in a sentence cannot be specified by a set of cross-references between lexical entries. In considering these points, it should be apparent that if the prior occurrence of semantically related words was found to facilitate lexical access during speech, then Forster's proposed semantic network of cross-references could certainly be extended to account for such sentential effects. On the other hand, it is unclear how this system of lexical interconnections could be modified to explain facilitative effects due to the meaning of sentence fragments rather than individual words.

In contrast to the search model, it seems that Morton's logogen model does predict that semantic context provided by either sentence fragments or semantically related items would facilitate lexical access during the processing of running speech. As previously described, both sensory and semantic information are accepted as input into the logogen system. According to Morton (1970), logogens cannot accept semantic information directly from each other. Instead, only semantic information sent to the logogen system via the cognitive (or contextual) system can lead to activation. Since the analysis of a sentence fragment can affect the state of the cognitive system, the semantic interpretation of the fragment can affect the entities in the logogen system. Thus, all logogens that share semantic properties with the sentence fragment will become partially activated. This, in turn, decreases the amount of sensory information needed for word recognition. Facilitative effects due to the prior occurrence of a semantically related word can also be explained by this contextual mechanism. Specifically, semantic information provided by previously accessed words is first trans. ferred from the logogen system to the cognitive system. Then the information is transferred back to the logogen system, so that all logogens sharing semantic attributes can be incremented. As we will note later, though, these facilitative effects may be bound to the temporal characteristics of the activation system. That is, since it may take time for the context to exert its effect, the model does not guarantee that facilitation will be observed. Nevertheless, the logogen model is certainly compatible with results that find such facilitation.

The second general issue on which the problem of semantic relatedness bears is that of lexical ambiguity. A number of ambiguity studies have addressed the question of whether lexical access is a context-dependent or a context-independent process. In the former case, prior context directs lexical access so that only a single relevant interpretation of the ambiguity is retrieved. In the latter case, multiple interpretations are retrieved and the role of context is to aid a postaccess decision process that selects one interpretation for further processing. The results of the ambiguity studies are 
themselves ambiguous. Some studies suggest that lexical retrieval is affected by context, while others support a context-independent model.

Many of the studies investigating the effect of lexical ambiguity and context on the retrieval process have used the phoneme-monitoring technique. In this task, subjects are asked to press a button when they hear a word beginning with a previously specified target sound. A phoneme can be identified as word-initial once it is known that the just-preceding phoneme is word-final. This can be known, in turn, once access to the preceding word has occurred. Thus, the identifica. tion of word-initial phonemes depends upon the time required for lexical look-up of the immediately preceding word. When the word-initial phoneme matches the specified target sound, subjects can respond. Time to make this response is taken to be a measure of the relative complexity of comprehension or, as in this case, of one of its components (i.e., lexical access).

Using this technique, Cairns and Kamerman (1975) and Foss (1970) found that the presence of a lexical ambiguity caused a momentary increase in processing load. This increased difficulty did not disappear when the ambiguity was preceded by a semantic context (Foss \& Jenkins, 1973). Foss and Jenkins concluded that the retrieval of lexical ambiguities from the mental lexicon is not affected by context. They proposed that the locus of context effects is at a later decision stage after multiple meanings of an ambiguous item have been retrieved. Similar conclusions have been drawn by $\mathrm{Cutler}$ and Foss (Note 2). This decision process supposedly intervenes between the retrieval of multiple meanings and the transference of one of those meanings into working memory. Both Cairns and Kamerman (1975) and Cutler and Foss (Note 2) proposed a contextindependent model of word identification in which the locus of context effects is on the decision process and not the retrieval process.

In recent work, however, Mehler, Segui, and Carey (1978) and Newman and Dell (1978) obtained data that call into question the results obtained by Cairns and Kamerman (1975), Foss (1970), Foss and Jenkins (1973), and Cutler and Foss (Note 2). The latter group of studies failed to effectively control the length of the ambiguous words and their unambiguous counterparts. They also did not control the phonological similarity of the ambiguous word or its control to the targetbearing word. Mehler et al. and Newman and Dell suggest that the confounding of these factors makes it difficult to attribute the results of the earlier experiments to the ambiguity variable. When these factors were appropriately controlled, the pattern of results obtained by the earlier ambiguity studies was not replicated. Mehler et al. (1978) concluded that some of the evidence "used to support the exhaustive computation hypothesis [i.e., the context-independent model] and to infirm the unitary perception hypothesis [i.e., the context-dependent model] is incorrect"' (p. 34).
Swinney and Hakes (1976) investigated the effects of ambiguity in a study not discussed by Mehler et al. (1978). Using stronger biasing context, Swinney and Hakes apparently eliminated the processing difficulty caused by lexical ambiguities. In their experiment, unlike the earlier studies, there was no momentary increase in processing load after a lexical ambiguity when preceded by biasing context. They concluded that access can be directed by context (see also Newman \& Dell, 1978, for a discussion of Swinney \& Hakes, 1976).

It is important to note that ambiguity studies such as those described here purport to be studying a special case of the general processes involved in sentence comprehension. Hence, claims about the effects of context on lexical access are not limited to ambiguity; they are claims about lexical retrieval in general. Additional information provided by directly studying the more general case of sentence processing using unambiguous words may prove useful in evaluating the contextdependent and context-independent models of lexical retrieval.

Consider a study in which prior context is related to the interpretation of an unambiguous word. The two models generate different predictions about what the results of such an experiment might be. A contextindependent model predicts that the retrieval of unambiguous words from the mental lexicon will not be facilitated by the prior context. This follows from the model's assumption that context exerts its facilitative effect on a postretrieval decision between multiple meanings. Of course, no such decision is necessary in the case of an unambiguous word, since there is only one meaning represented in the lexicon. On the other hand, a context-dependent model predicts that the prior context will facilitate the retrieval of unambiguous words from the lexicon. This follows from the conten. tion that biasing context has a direct effect on the speed of lexical look-up. The logogen model is a special case of the context-dependent model. Therefore, it too predicts that biasing context will have a direct effect on the speed of lexical access. Forster's (1976) lexical search theory is more closely related to a context-independent model; at least, this is the case when the stimuli are intact and presented in running speech. It should be noted that although the basic manipulation of using biasing context in unambiguous sentences has been used in some previous ambiguity studies (e.g., Foss \& Jenkins, 1973), the contrasts of context vs. no context for the unambiguous sentences were never actually tested, and the data do not appear straightforward.

There is in the literature, however, one experiment that investigated the effect of prior semantic context on the retrieval of unambiguous words during sentence processing. Morton and Long (1976) conducted a phoneme-monitoring study in which they manipulated the transitional probability between the first half of the sentence and an unambiguous target-bearing word. Reaction times (RTs) were shorter when the transitional 
probability was high (biasing semantic context) than when it was low (neutral context). Morton and Long argued that such results support the hypothesis that lexical access is speeded when a relevant semantic context has occurred within the sentence. In their study, the semantic context typically could not be pinpointed to a specific word or two. Rather, it was the interpretation of the sentence fragment that seemed to affect the transitional probability. A similar finding has also been reported by Underwood (1977). Underwood found that context provided by sentence fragments facilitated word recognition in a shadowing task. These results are obviously problematic for Forster's (1976) proposed model of lexical access.

The study reported here was designed to investigate the effect of prior occurrence of semantically related words on the retrieval of unambiguous words during sentence processing. In this study, unlike those conducted by Morton and Long (1976) and by Underwood (1977), it was possible to state explicitly the source of the semantic relationship. More specifically, the present work addresses a number of empirical issues concerning context effects and lexical retrieval within sentences. First and foremost, does the prior occurrence of semantically related words facilitate the retrieval of unambiguous words in sentences just as it does when those words are in a list? As noted earlier, the answer to this question has strong implications for models of lexical access; it can help us decide between contextdependent and context-independent models.

If there is a facilitative effect, then a second question can be asked, namely, what is the nature of this effect? Are varying degrees of context (i.e., multiple related words) associated with incremental amounts of facilitation, or is there a critical level of biasing context below which there is no facilitation and above which there is a constant amount of facilitation? The results of a lexical decision study reported by Schmidt (1976) suggest that incremental facilitation is likely. In that study, the number of semantically related words that preceded a test word was manipulated in a list of words. Schmidt found that more context words led to shorter RTs as well as to fewer errors.

The third question is concerned with the time course of context effects. Does context have its effects immediately, or must some period of time elapse before those effects are manifested? Once manifested, is the degree of facilitation constant over time, or does it gradually diminish? Answers to these questions will greatly influence our decision about which models of lexical processing are tenable.

In order to begin investigating these issues, the amount and source of prior context were varied within a set of experimental sentences. In each sentence, the verb was either related or unrelated to the noun that served as its direct object. Likewise, the adjective was either related or unrelated to that noun. Hence, an experimental sentence had four versions that differed from each other in the amount and source of prior context, as illustrated in Table 1. The task used in this experiment was phoneme monitoring. The target-bearing word always occurred immediately after the noun of interest. In the example, the target phoneme $/ \mathrm{p} /$ immediately follows the direct object "eye." If prior semantic context affects the lexical retrieval of "eye," then the effects should be reflected in phoneme-monitoring response times to the word-initial target $/ \mathrm{p} /$. Note that in this design there is a constant word prior to the targetbearing word. Hence, we have controlled the length of the word before the target-bearing word, a factor that has been found by Mehler et al. (1978) and Newman and Dell (1978) to affect phoneme-monitoring latencies. In addition, we have kept constant the word-initial phoneme of the word immediately preceding the target phoneme, which also has been shown to affect phonememonitoring response times (Newman \& Dell, 1978). ${ }^{2}$

Context-dependent models of sentence comprehension, in which prior semantic context facilitates the retrieval of subsequent related words from the mental lexicon, generate the following predictions. First, RTs should decrease as the amount of related prior context increases. Second, if the facilitation is incremental, then RTs should be longest when the noun is preceded by an unrelated verb and an unrelated adjective (no source of context); the shortest RTs should occur when both the preceding verb and the preceding adjective are related to the noun (two sources of context); intermediate RTs are expected when only the verb or only the adjective is related to the following noun (one source of context). A context-independent model of lexical retrieval predicts no facilitation (with one possible exception to be dealt with in the Discussion section).

The present experiment permits us to examine

Table 1

Examples of the Four Sentence Types (Target Phoneme: $/ \mathrm{p} /$ )

\begin{tabular}{lcc}
$\begin{array}{c}\text { Source of } \\
\text { Prior Context }\end{array}$ & $\begin{array}{c}\text { Amount of } \\
\text { Prior Context* }\end{array}$ & Experimental Sentence \\
\hline $\begin{array}{l}\text { None } \\
\text { Verb }\end{array}$ & 0 & The drunk concealed his aching eye probably without even realizing he was doing so. \\
Adjective & 1 & The drunk winked his aching eye probably without even realizing he was doing so. \\
Verb and Adjective & 1 & The drunk concealed his bloodshot eye probably without even realizing he was doing so. \\
The drunk winked his bloodshot eye probably without even realizing he was doing so.
\end{tabular}

Note-The critical lexical items and the target phonemes are italicized. $\quad{ }^{*}$ Numbers in this column indicate the number of words that are semantically related to the direct object. 
whether the effects of two sources of context (the verb and adjective) will interact. It seems reasonable to expect that they might. By virtue of being related to the same noun, the biasing verb and adjective are indirectly related to each other. Although the strength of this semantic relationship is weaker than the verbnoun and adjective-noun relationships, the possibility still remains for the occurrence of the verb to facilitate lexical processing of the related adjective. This, in tum, may lead to more rapid retrieval of the related noun. If this is true, then the magnitude of the facilitation provided by the related adjective will be greater when it is preceded by a related verb.

Specific predictions concerning the third issue, the time course of context effects, are more difficult to formulate. However, two aspects of the design of this study may permit us to begin making inferences about this matter from the results. First is the fact that the temporal distance from the verb to the noun is different from (greater than) the distance from the adjective to the noun. Second is the fact that the degree of relatedness between the verb and the noun and between the adjective and the noun was equated preexperimentally (see Method section for details). We assume that equal degrees of semantic relatedness are correlated with equivalent lexical facilitation. Fischler (1977) found that the magnitude of facilitation is correlated with semantic-relatedness ratings. Now suppose, for example, that the verb yields a greater facilitative effect than the adjective. This suggests that the function characterizing the time course of facilitation provided by a preceding related word has both a relatively slow rise time and a relatively slow decay time. That is, under these circumstances, the verb would have occurred early enough for its facilitative effect to manifest itself by the time the noun occurred, whereas not enough time would have elapsed for the adjective to exert its potentially equivalent influence. If, on the other hand, the adjective demonstrates a greater facilitative effect than the verb, this would suggest that the activation has both a relatively fast rise time and a relatively fast decay time. The effect due to the verb would presumably have decayed away by the time that the noun occurred. Finally, if the facilitation provided by the verb and the adjective are equivalent, this suggests that the rise time of the activation phenomenon is relatively fast (because the adjective is effective) and that the decay time is relatively slow (since the verb still has a facilitative effect). Meyer, Schvaneveldt, and Ruddy (Note 3) showed that when related words in lists are presented $4,000 \mathrm{msec}$ apart, the retrieval of the related words is still facilitated, although there is a considerable decrement in the amount of facilitation. More recently, investigators such as Becker and Killion (1977) and Neely (1977) have begun to examine the rise time of facilitation in list experiments. It remains to be seen whether the functions relating rise and decay times for facilitation are the same in lists as they are in sentences.
In light of the structure of sentences, it seems reasonable to speculate that rise times will be the same, but not decay times.

\section{METHOD}

\section{Design and Materials}

Thirty-two basic experimental sentences were constructed. Each sentence had four versions: The verb was either semantically related or unrelated to the following noun and, crossed with this variable, the adjective preceding that noun was either semantically related or unrelated to it. This defines four conditions. In order that each basic sentence could occur in each condition across the experiment, four material sets were constructed. Each material set contained all 32 basic sentences; eight sentences in each material set came from each of the four conditions. Across the material sets, each basic sentence occurred in all four conditions. The experiment was, therefore, a 2 (verb type: related/unrelated) by 2 (adjective type: related/ unrelated) by 4 (material sets) factorial, with the first two variables within subjects and the last between subjects.

The verb-adjective-noun triplets used in the experimental sentences were selected on the basis of relatedness ratings obtained for the adjective-noun and verb-noun pairs. The ratings were made by 127 undergraduate psychology students who did not participate in the main experiment. These ratings were collected in order to insure that the degree of relatedness between the verb and the noun was identical to that between the adjective and the noun. The subjects doing the rating were given a list of 100 simple sentences, 36 of which were filler sentences, all of the type, (det) $N V \operatorname{det}(a d j) ~ N$. In each sentence, either the verb or the adjective was underlined along with the direct object. The subjects' task was to judge how related the two underlined words were to each other. More specifically, subjects were asked to judge how much the first underlined word made them "think of" the second underlined word. No subject received both the verb and the adjective of a verb-adjective-noun triplet; subjects received either the verbnoun pair or the adjective-noun pair. Each subject made 50 judgments (32 experimental, 18 filler) of each pair type. Subjects used a 5-point rating scale to indicate their judgments, where 1 represented " $0 \%-20 \%$ of the time" and 5 represented " $80 \%-100 \%$ of the time." Only those triplets for which the degree of relatedness for both the verb and the adjective were judged to be between $60 \%$ and $100 \%$ by a minimum of $75 \%$ of the subjects were used in the main experiment. More specifically, the verb-noun pairs had a mean relatedness rating of $88.2 \%$, with a standard deviation of $6.40 \%$. The mean and standard deviation of the relatedness ratings for the adjective-noun pairs were $87.9 \%$ and $6.42 \%$, respectively.

Experimental sentences were constructed so that the word following the noun began with the target phoneme (e.g., the target is $/ \mathrm{p} /$ in Table 1 ). The six stop consonants were used as targets with the following frequencies of occurrence among the experimental sentences: $/ \mathrm{b} /, 9 ; / \mathrm{p} /, 5 ; / \mathrm{d} /, 8 ; / \mathrm{t} /, 2 ; / \mathrm{g} /, 4 ; / \mathrm{k} /, 4$. The beginning structure of each experimental sentence was always $N P V$ det adj $N$.

The frequency of the related and unrelated words for both the adjectives and the verbs were matched according to Kucera and Francis (1967) estimates. In addition, whenever possible, they were matched for syllable length and initial phoneme. (See the Appendix for the experimental sentences.)

Twenty-eight filler sentences were constructed. Eight of these did not contain the target phoneme, and the remainder varied the target position. The filler sentences were identical for each of the four material sets. The 60 sentences were randomized, with each basic sentence occurring in the same position for all material sets.

A male speaker recorded each of the four material sets on one channel of a tape. A pulse, inaudible to subjects, was placed 
on the second channel of the tape at the beginning of each target phoneme. The pulse started a timer that stopped when subjects pressed a button.

\section{Subjects}

The subjects were 44 undergraduate psychology students at the University of Texas at Austin who participated in the experiment in partial fulfillment of a course requirement. Eleven subjects were assigned to each of the four experimental tapes (material sets).

\section{Procedure}

Subjects were tested in groups of one to six, with the experimenter and subjects occupying adjoining rooms. Each subject was seated in a booth out of direct sight of the others.

Instructions describing the subjects' task were recorded at the beginning of each experimental tape. The instructions and the test sentences were presented binaurally over headphones. Subjects were told to lightly rest the index finger of their preferred hand on the button in front of them. They were instructed to listen for a word-initial sound (i.e., "/b/as in Bob") and to press the button as quickly as possible when they heard it. A trial consisted of the word "ready," specification of the target phoneme, and the presentation of a sentence. Subjects were given three practice sentences, one of which did not contain the target phoneme. After the experimenter answered questions clarifying any uncertainties regarding the instructions, the experimental and filler sentences were presented.

Subjects were forewarned in the instructions that a comprehension test would be administered after hearing all the sentences. This instruction emphasized the importance of paying close attention to the sentences. Immediately following presentation of the test sentences, subjects were given a printed comprehension test. This test was a recognition test consisting of 20 sentences, half of which the subjects had heard during the experiment and half of which they had not heard. All of the sentences on the comprehension test that had been presented during the experiment were fillers. Since these were identical for each of the four experimental tapes, the same test was administered to all the subjects. Subjects were asked to indicate by a check mark those sentences that they had heard during the experiment. Of the sentences that subjects had not heard, half were derived from actual filler sentences in one of two ways. Either many of the words were identical to those that occurred in the originally presented filler sentence, or the derived filler sentence was structurally similar to the original sentence. The following is an example of an actual filler sentence that subjects heard during the experiment and a sentence derived from it that occurred on the comprehension test: The sniper assassinated the young president with a rifle (filler). The president was assassinated while he was campaigning (test). The remaining sentences were not related to any of those presented during the experiment. The only data analyzed were those obtained from subjects who were correct on 15 or more test sentences (44 subjects out of 74 tested).

\section{RESULTS}

The mean RTs for each subject in each of the four experimental conditions were computed and subjected to an analysis of variance. RTs longer than $1,500 \mathrm{msec}$ were omitted from the analysis, since such lengthy responses often reflect a reprocessing of input. Missing data points that resulted either from the elimination of RTs over $1,500 \mathrm{msec}$ or from failures to respond were filled in according to the procedure described by Winer (1971).

The results for each condition are shown in Table 2 .
Table 2

Mean Phoneme-Monitoring Latencies (in Milliseconds)

\begin{tabular}{ccccc}
\hline \multirow{2}{*}{$\begin{array}{c}\text { Verb } \\
\text { Context }\end{array}$} & \multicolumn{3}{c}{ Adjective Context } \\
\cline { 2 - 5 } & \multicolumn{2}{c}{ Unrelated } & \multicolumn{2}{c}{ Related } \\
\hline Unrelated & 482 & $(0)$ & 462 & $(1)$ \\
Related & 460 & $(1)$ & 438 & $(2)$ \\
\hline
\end{tabular}

Note-Numbers in parentheses indicate the amount of prior context (i.e., the number of semantically related words) in the four conditions.

The pattern of RTs is that predicted by the contextdependent model. The no-context condition yielded the slowest RTs; two sources of context resulted in the fastest times; intermediate RTs were found for one source of context.

The analysis of variance by subjects and items showed a significant main effect for each source of context [for adjectives: $F_{1}(1,40)=9.06, p<.004, F_{2}(1,31)=5.95$, $p<.02$; for verbs: $F_{1}(1,40)=6.48, p<.01, F_{2}=5.15$, $p<.03$ ] . The min $F^{\prime}$ statistic (Clark, 1973) was marginally significant for both effects $\left[\min \mathrm{F}^{\prime}(1,64)=3.59\right.$, $\mathrm{p}<.10$; and $\min \mathrm{F}^{\prime}(1,67)=2.86, \mathrm{p}<.10$, for adjectives and verbs, respectively]. No other main effects or interactions were significant. Foss, Cirilo, and Blank (Note 4) have replicated the results of this experiment. The results of the analysis of variance performed on these data paralleled the findings of the present study except that min $F^{\prime}$ s were significant.

Comparison by orthogonal weighting coefficients showed that no source of context was significantly different from one source of context (adjective and verb pooled) $[F(1,40)=4.05, p<.05]$. A second comparison by orthogonal weighting coefficients (not independent from the first set of orthogonal weights) showed that two sources of context differed significantly from one source of context (again, adjective and verb pooled) $[\mathrm{F}(1,40)=7.91, \mathrm{p}<.01]$.

Error rates for the four conditions were: no source, .12; one source (verb), .08; one source (adjective), .09 ; two sources, .07. These error rates were subjected to an analysis of variance treating subjects as a random variable. The results showed a significant main effect of context condition $[F(3,40)=2.61, p<.05]$. All possible pairwise comparisons (six) were tested using orthogonal weighting coefficients. These comparisons revealed that the significant main effect of context was totally attributable to the contrast between no source and two sources of context $[F(1,40)=6.90, p<.01]$. Thus, the probability of making an error in responding to a target phoneme is significantly greater when there is no prior context than when there are two sources of prior context. ${ }^{3}$ This finding is consistent with the notion that the prior occurrence of semantically related words facilitates word recognition.

\section{DISCUSSION}

In the introduction, we asked the question, does the 
prior occurrence of semantically related words facilitate lexical retrieval during sentence comprehension? The answer to this question appears to be yes. We found that the processing of unambiguous words in sentences requires less time when preceded by semantically related words than when preceded by more neutral words. This finding is consistent with context-dependent models of lexical access, including the logogen model. It is also consistent with. the earlier findings of Morton and Long (1976). The present results suggest that search models of lexical access such as that proposed by Forster (1976) must permit the rapid use of semantic information to reduce the search space during the processing of running speech. Forster's model needs to be revised accordingly.

The present findings are not consistent with a strong version of the context-dependent model of lexical access in which prior semantic context is assumed to affect only the selection of a single meaning from among those already retrieved. Such a model was formulated to account for the results obtained from experiments on the processing of lexically ambiguous sentences. The results presented here demonstrate that such models are unable to account for the more general case of understanding unambiguous sentences.

However, there is an alternative interpretation of the present results that, in effect, does not require a context-dependent model of lexical retrieval. The target phoneme for each of the experimental sentences occurred at a clause boundary. A number of researchers have suggested that information contained within a clause is not integrated until a clause boundary is reached (e.g., Fodor, Bever, \& Garrett, 1974). An advocate of this viewpoint might argue that prior semantic context facilitates the integration of the words within a clause (or its constituents) in to a more holistic representation. According to this view, then, context affects the speed of integrating the lexical items rather than the process of gaining access to them. Thus, we have an apparent impasse: Semantic context can either (1) affect access or (2) affect integration. However, there is a basis for making a choice between these alternatives. Recall that related items lead to faster responses in the lexical decision task when words occur in lists (e.g., Meyer \& Schvaneveldt, 1976; Schmidt, 1976). In such studies, the question of integration does not arise; the faster response times must be due to faster retrieval of the critical item when it is preceded by a semantically related word. Therefore, until different predictions derived from these two models are experimentally sustained, parsimony dictates that a retrieval explanation be adopted, since it accounts for the results obtained with both sentences and lists.

A second question that we raised in the introduction was whether varying degrees of context are associated with varying amounts of facilitation. The answer is yes. Two related words led to significantly faster lexical retrieval than did one. This incremental pattern of facilitation, analogous to the finding reported by
Schmidt (1976), is consistent with a threshold model such as that proposed by Morton (1969). In his model, both sensory and contextual information combine to bring a lexical concept above its threshold value (i.e., to activate it). According to such a model, there is a tradeoff relation between contextual and sensory information: The more there is of the former, the less is needed of the latter for activation. Interestingly, we found that the effect of prior semantic context is additive: The amount of facilitation provided by two sources of context was equal to the sum of the facilitation provided by each source independently. When compared to the no-context condition, RTs were $20 \mathrm{msec}$ faster when a related adjective was present, while the presence of a related verb decreased RTs by $22 \mathrm{msec}$. When both the adjective and the verb were related to the noun, there was $44 \mathrm{msec}$ of facilitation. This is nearly perfect additivity. If additivity proves to be a general finding, it has implications for the form of a viable threshold model.

This additivity result suggests that the convergence of multiple facilitative effects upon a single lexical item leaves unaffected the amount of facilitation provided by each contributor. This was a somewhat surprising result (recall our earlier discussion about the possibility of an interaction between the verb and the adjective effects). However, intuitions suggest that there are boundary conditions on obtaining additivity. For example, there is probably a ceiling effect such that increasingly more context will have diminishing effects on the degree to which an item is activated. One might expect the amount of facilitation to reach asymptote when context uniquely determines the occurrence of a given word. In that case, additional context could no longer aid retrieval. In fact, Schmidt (1976) found a ceiling on the amount of facilitation provided by context words. Presenting eight context words served to increase the accessibility of related words to a maximum. Also, it may be that a certain minimal amount of context is required before its facilitative effects can be observed. This may explain why the facilitative effect of a related adjective was not enhanced by the prior occurrence of a related verb. The related verbs and adjectives were only indirectly related to each other in our materials. The strength of this relationship may have been below the critical level of relatedness that is needed for facilitation. Perhaps if we increased the degree of relatedness between the verb and adjective (at least to a level comparable to that between the verb-noun and adjective-noun pairs used in this experiment), an interaction between the verb and adjective effects would occur. Further research is definitely needed.

Our third question concerned the time course of the facilitation. Because the same words were not used as both verbs and adjectives, our results can be suggestive at best-and they are. The fact that the related verb yielded a significant facilitative effect suggests that the time course of the facilitation has a relatively slow 
decay time (at least $1 \mathrm{sec}$ ). The verb was always more distant from the noun than was the adjective, so in order for it to have exerted its influence on the retrieval of the noun, it must have maintained its facilitative effect for at least this period of time. Likewise, the related adjective yielded a significant (and equivalent) facilitative effect, even though the related noun occurred immediately after it. Thus, it appears that the facilitation has a very rapid rise time in addition to a relatively slow decay time.

In summary, we have demonstrated that lexical access during sentence processing is facilitated by the prior occurrence of semantically related words. These results, along with those of Morton and Long (1976), suggest that lexical access is most appropriately viewed as a context-dependent process wherein prior context has a direct effect on the speed of lexical look-up. Lexical search models need to incorporate these findings. In addition, we have found that increasing amounts of prior context are associated with incremental facilitation. Further, we have suggested that the facilitative effects of related words have very rapid rise times and relatively slow decay times. To the extent that our description of the time course of facilitation has been inferential and perhaps speculative, we have illustrated the need for further research on this issue.

\section{REFERENCE NOTES}

1. Forster, K. I. Levels of processing and the structure of the the language processer. In W. E. Cooper \& E. Walker (Eds.), Sentence processing: Psycholinguistic studies presented to Merrill Garrett. Book in preparation, 1978.

2. Cutler, A., \& Foss, D. J. Comprehension of ambiguous sentences: The locus of context effects. Paper presented at the annual meeting of the Midwestern Psychological Association, Chicago, May 1974.

3. Meyer, D., Schvaneveldt, R., \& Ruddy, M. Activation of lexical memory. Paper presented at the annual meeting of the Psychonomic Society, St. Louis, 1972.

4. Foss, D. J., Cirilo, R., \& Blank, M. A. Semantic facilitation and lexical access during sentence processing: $A n$ investigation of individual differences. Manuscript submitted for publication, 1978.

5. Foss, D. J., Blank, M. A., \& Harwood, D. A. Identifying the speech codes. Manuscript submitted for publication, 1978.

\section{REFERENCES}

BeCKer, C. A., \& Killion, T. H. Interaction of visual and cognitive effects in word recognition. Journal of Experimental Psychology: Human Perception and Performance, 1977, 3, 389-401.

Bransford, J. D., \& Johnson, M. K. Contextual prerequisites for understanding: Some investigations of comprehension and recall. Journal of Verbal Learning and Verbal Behavior, 1972, 11, 717-726.

Bransford, J. D., \& McCarrell, N. S. A sketch of a cognitive approach to comprehension: Some thoughts about understanding what it means to comprehend. In W. B. Weimer \& D. S. Palermo (Eds.), Cognition and the symbolic processes. Hillsdale, N.J: Lawrence Erlbaum, 1974.

Calrns, H. S., \& Kamerman, J. Lexical information processing during sentence comprehension. Journal of Verbal Learning and Verbal Behavior. 1975, 14, 170-179.
Cole, R. A. Listening for mispronunciations: A measure of what we hear during speech. Perception \& Psychophysics, $1973,1,153-156$.

Clark, H. H. The language-as-a-fixed-effect fallacy: A critique of language słatistics in psychological research. Journal of Verbal Learning and Verbal Behavior, 1973, 12, 335-339.

Dooling, D. I., \& Lachman, R. Effects of comprehension on the retention of prose. Journal of Experimental Psychology, 1971, 88, 216-222.

FIsCHLER, I. Semantic facilitation without association in a lexical decision task. Memory \& Cognition, 1977, 5, 335-339.

Fodor, J. A., BeVer, T. G., \& Garrett, M. F. The psychology of language. New York: McGraw-Hill, 1974.

Forster, K. I. Accessing the mental lexicon. In R. J. Wales \& E. Walker (Eds.), New approaches to language mechanisms. Amsterdam: North-Holland, 1976. Pp. 257-287.

Foss, D. J. Some effects of ambiguity upon sentence comprehension. Joumal of Verbal Learning and Verbal Behavior, 1970, 9, 699-706.

Foss, D. J., \& Jenkins, C. M. Some effects of context on the comprehension of ambiguous sentences. Journal of Verbal Learning and Verbal Behavior, 1973, 12, 577-589.

KUCERA, H., \& Francis, W. N. Computational analysis of present day American English. Providence, R.I: Brown University Press, 1967.

Marslen-Wilson, W. Linguistic descriptions and psychological assumptions in the study of sentence perception. In R. J. Wales \& E. Walker (Eds.), New approaches to language mechanisms. Amsterdam: North-Holland, 1976. Pp. 203-229.

Mehler, J., Segui, J., \& Carey, P. Tails of words: Monitoring ambiguity. Journal of Verbal Learning and Verbal Behavior, 1978, 17, 29-35.

Meyer, D., \& SChVaneveldt, R. Facilitation in recognizing pairs of words: Evidence of a dependence between retrieval operations. Journal of Experimental Psychology, 1971, 90, 227-234.

Meyer, D., \& SChVaneveldt, R. Meaning, memory structure and mental processes. Science, 1976, 192, 27-33.

Morton, J. The interaction of information in word recognition. Psychological Review, 1969, 76, 165-178.

Morton, J. A functional model for memory. In D. A. Norman (Ed.), Models of human memory. New York: Academic Press, 1970.

Morton, J., \& Long, I. Effect of word transitional probability on phoneme identification. Journal of Verbal Learning and Verbal Behavior, 1976, 15, 43-51.

NeELY, J. H. Semantic priming and retrieval from lexical memory: Roles of inhibitionless spreading activation and limited-capacity attention. Journal of Experimental Psychology: General, $1977,106,226-254$.

Newman, J. E., \& Dell, G. S. The phonological nature of phoneme monitoring: A critique of some ambiguity studies. Journal of Verbal Learning and Verbal Behavior, 1978, 17, 359-374.

Schmidt, R. On the spread of semantic excitation. Psychological Research, 1976, 38, 333-353.

Schuberth, R. F., \& Eimas, P. Effects of context on the classification of words and nonwords. Journal of Experimental Psychology: Human Perception and Performance, 1977, 33, 27-36.

Shankweiler, D., Strange, W., \& Verbrugge, R. Speech and the problem of perceptual constancy. In R. Shaw \& J. Bransford (Eds.), Perceiving, acting, and knowing. Hillsdale, N.J: Lawrence Erlbaum, 1977.

Swinney, D. A., \& Hakes, D. T. Effects of prior context upon lexical access during sentence comprehension. Journal of Verbal Learning and Verbal Behavior, 1976, 15, 681-689.

Tulving. E.. \& Gold, C. Stimulus information and contextual information as determinants of tachistoscopic recognition of words. Journal of Experimental Psychology, 1963, 66. 319-327. 
Underwood, G. Contextual facilitation from attended and unattended messages. Journal of Verbal Learning and Verbal Behavior, 1977, 16, 99-106.

Warren, R. M., \& Sherman, G. L. Phonemic restorations based on subsequent context. Perception \& Psychophysics, $1974,16,150-156$.

WINER, B. J. Statistical principles in experimental design. New York: McGraw-Hill, 1971.

\section{NOTES}

1. Throughout this paper, the following terms are used interchangeably: word identification, lexical retrieval, lexical access, lexical look-up, and word recognition.

2. Careful readers may have noted that the target phoneme occurred on the word of interest in the Morton and Long (1976) experiment, while it occurred after the object noun of interest in the present study. This difference can be critical in phonememonitoring experiments (Foss, Blank, \& Harwood, Note 5), but it is not critical for our present line of argument.

3. The error rates reported here are based only on misses (i.e., RTs over 1,500 msec or failures to respond at all). Data regarding false-alarm rates in this experiment were not collected.

\section{Appendix}

Sentences Used in the Main Experiment

1. The strong afternoon sun (scorched/tanned) Helen's (flawless/sunburnt) skin by the third day of her Caribbean vacation.

2. The drunk (concealed/winked) his (aching/bloodshot) eye $p$ robably without even realizing he was doing so.

3. The commander-in-chief (translated/mailed) the (disquieting/special-delivery) letter proposing that future requests for foreign aid be denied.

4. The teacher (pondered/punctuated) the (disjointed/ ungrammatical) sentence $b$ ut then deleted it.

5. The pioneer family (repelled/extinguished) the (dangerous/burning) fire totally by themselves.

6. The professor (discounted/graded) the (exasperating/ multiple-choice) exam carelessly prepared by the two teaching assistants.

7. Many industrial factories (spoil/pollute) our (irreplacible/ breathable) air despite the severe penalties imposed upon them.

8 . The young married couple (noticed/adopted) the (displaced/orphaned) child practically right away.

9. The processing plant (re-examined/pasteurized) the (unadulterated/homogenized) milk delivered fresh from the farm.

10. The athlete (relinquished/fumbled) the (slimy/punted) football down around the twenty yard line.
11. The student (headed/drove) the (dirty/parked) car back into a tree when the instructor wasn't looking.

12. The deranged physicist (rigged/detonated) the (dangerous/ atomic) bomb, $c$ ausing widespread havoc.

13. The finalist (recited/spelled) the (challenged/misspelled) word correctly after reconsidering her initial response.

14. The farmer's wife (inspected/poached) the (untainted/ unhatched) eggs gathered this morning.

15. The secretary (redid/shampooed) her (messy/frizzy) hair $b$ efore going to work.

16. The young writer (heard/asked) the (uninteresting/ unanswerable) question $d$ uring the press conference.

17. John (craved/toasted) the (packaged/whole-wheat) bread given to him by his mother on visiting day.

18. The hot summer days (matured/ripened) the (brownish/ citrus) fruit growing on the trees.

19. The housekeeper (misplaced/watered) the (multicolored/ leafy) plant $b$ elonging to her employer.

20. The direct sunlight (discolored/wilted) the (reddish/ blossoming) flowers placed in the vase on the window.

21. The veteran performer (hated/sang) the (acclaimed/ melodious) song composed by the innovative young musician.

22. The youngster's coach (disqualified/peddled) the (collapsible/10-speed) bicycle given to the contestant by the sponsors of the race.

23. The amateur (supervised/filmed) the (barbaric/ pornographic) movie $d$ uring her free time.

24 . The young man (scrubbed/preheated) the (remodeled/ microwave) oven before cooking the frozen pizza.

25. The gunman (patrolled/piloted) the (unscheduled/ skijacked) airplane destined for Cuba.

26. Plain soap and water (cleansed/healed) the (filthy/ infected) wound better than any other possible treatment.

27. The professional con man (grabbed/dealt) the (overzsized/ shuffled) cards together with the marked deck.

28. The newly appointed inspector (investigated/arrested) the (elderly/convicted) criminal despite contrary orders from his superiors.

29. The maid (labeled/ironed) the (undamaged/laundered) clothes $b$ efore shipping them off to the Salvation Army.

30. The actress (moistened/puckered) her (enticing/kissable) lips $b$ etween takes of the love scene.

31. The assistant (comforted/diapered) the (finicky/teething) infant $p$ rior to administering the injection.

32. The stuntman (bandaged/saddled) the (limping/galloping) horse $d$ uring the chase scene.

Note-The target phoneme is italicized.

(Received for publication July 13, 1978; revision accepted October 26,1978 .) 